\title{
Power Makes You Selfish? When and How Power Affect Pro-Social Behavior
}

\author{
Yiming Cai, Yaozhong Liu \\ School of Management, Jinan University, Guangzhou, China \\ Email: cymcaiyiming@outlook.com
}

How to cite this paper: Cai, Y. M., \& Liu, Y. Z. (2019). Power Makes You Selfish? When and How Power Affect Pro-Social Behavior. Psychology, 10, 748-766. https://doi.org/10.4236/psych.2019.105049

Received: April 1, 2019

Accepted: April 27, 2019

Published: April 30, 2019

Copyright $\odot 2019$ by author(s) and Scientific Research Publishing Inc. This work is licensed under the Creative Commons Attribution International License (CC BY 4.0).

http://creativecommons.org/licenses/by/4.0/

\begin{abstract}
Power is the basic component of our society. In social psychology, the study of power usually focuses on the sense of power. Early research always focused on the negative effects of power, but it is difficult to explain the complex effects of sense of power. Therefore, from the perspective of moral self-image, this study attempts to integrate the differential effects of sense of power and explores its potential moderating and mediating role. Therefore, we use three studies to explore these effects and find that individual's sense of power can reduce their pro-social behavior, while moral self-image can moderate this effect. In addition, the moderating effect of moral self-image is mediated by perceived responsibility.
\end{abstract}

\section{Keywords}

Sense of Power, Moral Self-Image, Pro-Social Behavior, Perceived

Responsibility

\section{Introduction}

As a social phenomenon, power exists widely in every aspect of our daily life and it is a fundamental element in social structures (Brass \& Burkhardt, 1993; Magee \& Galinsky, 2008; Boehm \& Flack, 2010; Rus, 2010). Whenever we talk about the power, people always think of its negative side. Most people think that high-power is always profit-seeking, self-interested, and careless. Although it is true that many studies in the past have shown that with the improvement of sense of power, the individual's pro-social behavior does appear to decrease (Fiske, 1993; Bargh, Raymond, Pryor, \& Strack, 1995; Galinsky et al., 2003; Keltner et al., 2003; Gruenfeld, Inesi, Magee, \& Galinsky, 2008; Lammers, Stapel, \& Galinsky, 2010; Rucker, Dubois, \& Galinsky, 2011), subsequent research also pointed out the different view. They pointed out that power does not fundamen- 
tally change an individual. It can only promote the expression of peoples' characteristics, which it is to say, if an individual has some kind of pro-social trait, then his or her pro-social behavior will also increase with the improvement of sense of power (Galinsky et al., 2010). That is to say, simply explaining the influence of power from a single perspective is not enough to explain its complexity.

The moral self-image, which is an individual's perception of his current moral level, can also have an important impact on one's pro-social behavior. Early research showed that moral self-image can positively predict the level of pro-social behavior, and individuals with high moral self-image tend to make more pro-social behaviors and demonstrate the effect of moral consistency (Aquino \& Reed, 2002; Young, Chakroff, \& Tom, 2012). However, subsequent studies have also found that the opposite effect of moral consistency is, as the moral self-image is improved, the pro-social behavior is reduced: that is, the phenomenon of moral balance is presented (Jordan, Mullen, \& Murnighan, 2011). This shows that the impact of moral self-image on pro-social behavior is also complex.

\subsection{The Moderating Role of Moral Self-Image}

On the one hand, the sense of power can promote the expression of individual traits. On the other hand, moral self-image, as a moral trait, impacts the pro-social behavior equally complex (Young, Chakroff, \& Tom, 2012; Zhu, Jin, Wan, \& Li, 2017). Do the complex effects of sense of power and moral self-image have something in common? According to Regulatory Focus Theory (RFT), the individuals with high powers have the ability to use resources to earn rewards (Keltner et al., 2003), which makes them try to see characterized goals as ideals and aspirations, and therefore more inclined to use promoted focus, and on the other hand, low-power individuals which are in a resource-poor environment need to cooperate with others to get the things done (Zaal, van Laar, Ståhl, Ellemers, \& Derks, 2011), so they intended to use prevented focus and see their goals as what "should be" done.

And according with the logic of RFT, although moral self-image also has two distinct effects on pro-social behavior, we can find a rule that when moral consistency occurs, individuals can image the moral self as "ideal self "and "goal to achieve" (Mullen \& Miller, 2016), thus showing a consistent tendency in subsequent tasks; and when moral balance occurs, individuals tend to image current moral self as "should self" and "already made progress", under this "should" mode, high moral self-image represents the individual's progress in pursuing moral goals, and low moral self means that the individual has not yet completed his own moral goals, and thus shows a balance effect in subsequent tasks.

In summary, we can infer that the promote-focused high sense-of-power individuals will link the moral self-image with the "ideal self", thus people will express the consist behavioral tendency with their moral self-image, that is, showing moral consistency; and the prevent-focused low sense-of-power individuals will connect the moral self-image with the "should self", thus express the behavioral tendency contrary to their moral self-image, that is, the moral balance effect. 


\subsection{Perceived Responsibility and the Prosocial Behavior}

Pro-social behavior is influenced by many factors, but one of the key determinants is that individuals need to think that they need to help others and be responsible for the well-being of others (Darley \& Latane, 1968; Schwartz, 1977; Rachman, Thordarson, Shafran, \& Woody, 1995; Lerner \& Tetlock, 1999), that is, before the emergence of social behavior, "potential helpers need to perceive a sense of responsibility to alleviate the needs of others" (Schwartz \& David 1976: p. 406). For example, individuals who believe they need to be responsible for the poor will generate more donations and believe that they need to be environmentally responsible individuals to generate more environmental behaviors (Winterich \& Zhang, 2014; Wu \& Yang, 2018; Zhu, Wong, \& Huang, 2019).

Therefore, for those individuals with high power, which tend to use promoted focus, when activate high moral self-image, they will express high moral self-image as their moral ideals and extract moral identity from high MSI. Guided by their moral identity, they will consider themselves more responsible for caring others (Aquino, Reed, Thau, \& Freeman, 2007; Reed et al., 2016), thus making more pro-social behaviors (Mullen \& Miller, 2016); and when activating their low MSI, those people with high sense of power will pay more attention to their self-interest, in order to further gain more self-interest, these individuals will diminish the attention to the needs of others, so their perceived sense of helping others will also be relatively low, pro-social behavior is naturally less.

Therefore, the study uses this relationship between responsibility and pro-social behavior to explain the meditated moderation mechanism. In summary, we can think that the individual moral self-image can moderate the influence of the sense of power on pro-social behavior, which is mediated by the perceived responsibility, and puts forward three hypotheses:

H1: Sense of power can negatively affect an individual's pro-social behavior;

H2: Moral self-image can moderate the influence of power on pro-social behavior;

H3: The moderated effect of moral self-image is mediated by the perceived responsibility sensed by the others.

In summary, this study uses questionnaires and experimental research methods to try to research the influence of sense of power on pro-social behavior from the perspective of moral self-image. Based on the Regulatory Focus Theory, we explore a mediated moderator model of moral self-image.

\section{Study 1: Preliminary Study on the Relationship between Sense of Power and Pro-Social Behavior}

Study 1 uses a questionnaire survey to explore the relationship between general power and pro-social will, and whether moral self-image can regulate the influence of power on pro-social intention.

\subsection{Participants}

We send 150 questionnaires to the participants which were randomly recruit in 
Jinan University (none of them are majored in psychology), and 134 valid questionnaires were finally collected. The effective recovery rate was $89.33 \%$. There were 9 males (44\%) and 75 females (56\%) with an average age of 23.03 (SD = 2.06) years old. The participants received a small amount of reward after completing the research.

\subsection{Measurement}

1) Sense of power scale: using the Sense of Power Scale compiled by Anderson et al. (2012) to measure the general sense of power, the scale contains a total of eight items (Cronbach's $\alpha=0.71$ ).

2) Moral self-image scale: using the Moral Self-image Scale compiled by Jordan et al. (2012) to measure the moral self-image, the scale contains a total of nine items (Cronbach's $\alpha=0.77$ ).

3) Pro-social intention scale: using the six items scale made by Jordan, Mullen and Murnighan in 2011 (Cronbach's $\alpha=0.70$ ) to measure the pro-social intention.

4) Demographic data: including the gender and age of the subjects.

\subsection{Results}

After centralizing the sense of power and moral self-image, the pro-social intention is used as the outcome variable, the mean of sense of power, the mean of moral self-image, and the product of the two are predictors, and launch the regression analysis. After controlling for gender and age, the results are shown in Table 1. It was found that the sense of power $(\beta=-0.17, t=-2.31, p<0.05)$ was able to significantly predict the pro-social will and negatively verified $\mathrm{H} 1$. The main effect of moral self-image is not significant $(\beta=0.06, t=0.79, p=0.43)$. The coefficient of power $\times$ moral self-image has a significant regression coefficient $(\beta=0.16, t=3.73, p<0.001)$.

Simple slope test found that when the moral self-image is low (M-1SD), the sense of power can significantly negatively predict the pro-social will $(\beta=-0.40$, $t=-4.27, p<0.001)$; When the moral self-image is high $(\mathrm{M}+1 \mathrm{SD})$, the sense of power can't predict the pro-social intention $(\beta=0.05, t=0.53, p=0.60)$, as shown in Figure 1.

\subsection{Discussion}

In the first study, the pro-social intention is taken as the dependent variable. We discussed the influence of the sense of power and moral self-image on the pro-social intention. The study found that the sense of power can negatively predict the pro-social intention of the individual, which is consistent with the results of previous studies. That is to say, with the improvement of individual power, the pro-social intention is relatively reduced, and $\mathrm{H} 1$ is supported.

The moral self-image has a significant moderated role. When the individual's moral self-image is low, the sense of power can negatively predict his pro-social intention, because for individuals with high power who tend to use the promotion 
Table 1. Regression analysis of sense of power and pro-social intention.

\begin{tabular}{|c|c|c|c|}
\hline & \multicolumn{3}{|c|}{ Pro-social intention } \\
\hline & $\beta$ & & $t$ \\
\hline Gender & 0.01 & & 0.11 \\
\hline Age & -0.04 & & -1.47 \\
\hline Sense of Power $(\mathrm{P})$ & -0.17 & & $-2.31^{*}$ \\
\hline Moral self-image (M) & 0.06 & & 0.79 \\
\hline $\mathrm{P} \times \mathrm{M}$ & 0.16 & & $3.73^{\star * *}$ \\
\hline $\mathrm{R}^{2}$ & & 0.15 & \\
\hline$\Delta \mathrm{R}^{2}$ & & 0.09 & \\
\hline $\mathrm{F}$ & & $4.43^{* * *}$ & \\
\hline
\end{tabular}

Note: ${ }^{*} p<0.05,{ }^{* *} p<0.01,{ }^{* * *} p<0.001$.

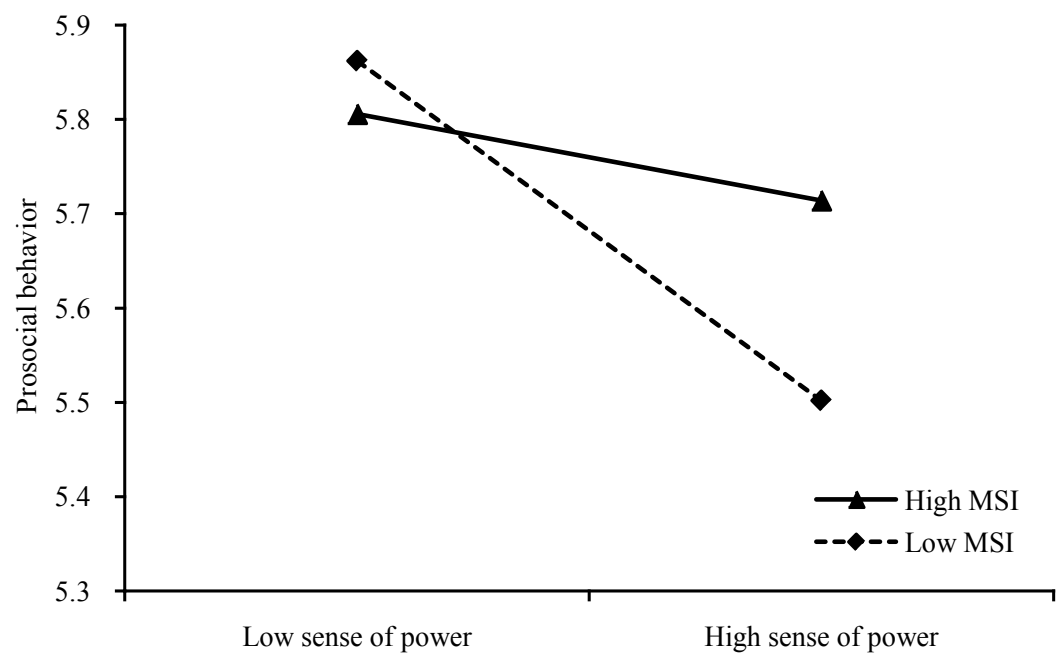

Figure 1. Simple slope test of pro-social intention.

focus, the low moral self-image strengthens the self-interested goal of high-power individuals, so their pro-social intention is relatively low. While for low-power individuals, they tend to use prevention focus, lower moral self-image creates a sense of threat to their own moral cognition, so they tend to bring the lower moral self-image closer to the appropriate level, that is, individuals with low power will hope to improve their self-image by increasing pro-social behavior. When the individual's moral self-image is higher, the sense of power cannot significantly predict the individual's pro-social intention, and $\mathrm{H} 2$ has not been supported. And whether the sense of power can predict its pro-social level, we continue to explore this issue through Study 2 and Research 3.

\section{Study 2a: The Effect of Sense of Power and MSI on Helping Time}

Based on the results of Study 1, Study 2a is using paper-and-pen experiment to study further, and the dependent variable is changed to the help time of the participants in the simulated pro-social situation. On the one hand, experimental 
research has made up for the shortcomings of the relevant research in the study 1 , and also increased the coverage of the dependent variable measurement.

\subsection{Participants}

We recruit a total of 150 participants in Jinan university. Among them, 8 subjects did not complete the recall task initiated by the power, and the data was not included in the final analysis. In the end, there were 142 valid participants, including 72 males and 70 females with an average age of $22.74(\mathrm{SD}=2.43)$ years.

\subsection{Methods}

The experiment adopts a mixed design, in which the sense of power is the inter-subject variable, the moral self-image is the internal variable of the subject, and the simulated helping time is measured as the dependent variable. Because the emotion can also affect the pro-social behavior, so we consider emotion of the subject as a control variable (Tangney, Stuewig, \& Mashek 2007; Algoe \& Haidt, 2009; Doorn, Zeelenberg, \& Breugelmans, 2014).

1) Manipulation of sense of power: the classic start-up paradigm of power-the story recall method (Galinsky et al., 2003) initiates the sense of power of the participants, asking the participants to recall their own experiences of lack of power and write their own It's really a memory experience. And using 4items (Cronbach's $\alpha=0.88$ ) to test the initiation of power, "I feel that I have power", "I feel that I am in control of the direction of things", "I feel that my will is not important", "I feel that I have no influence."

2) Moral self-image measurement: using the moral self-image scale, same as study 1 (Cronbach's $\alpha=0.87$ ).

3) Emotional Self-Assessment Questionnaire: using Van de Vyver's (2015) Emotional Self-Assessment Questionnaire (Cronbach's $\alpha=0.76$ ), which contains 10 items (Julie \& Abrams, 2015).

4) Demographic data: including the gender and age of the subjects.

\subsection{Procedures}

Firstly, manipulated the sense of power, and then asked the participants to complete manipulation check. Then, measure the moral self-image. After the measurement of the moral self-image, participants were asked to fill in the emotion scale for control as a covariate. To ensure that the donor's helping behavior is not related to emotions, and finally measure the participants' helping time in the simulated situation. And then, participants were told that the research is ended. After all this, another experimenter came in and told participants that he need to ask them a favor, and asked if the participants can help him complete his experiment, and if they do, long it will take, from 0 to 60 minutes in 5 minute intervals. After the whole experiment is over, the subject is explained accordingly.

\subsection{Results}

Manipulation check: Through independent sample $t$-test, the scores of the 
high-power-sensing group $(M=5.13, S D=0.82)$ were significantly higher than those of the low-power-sensing group $(\mathrm{M}=2.89, \mathrm{SD}=0.61), t(140)=18.54, p<$ 0.001 , the sense of power is successfully manipulated.

Emotion: Because there is a high correlation between different emotions, 10 kinds of emotions are analyzed by exploratory factors, and the problem of collinearity is avoided while dimension reduction. The results show that 10 emotions are divided into two factors: "Pride," "Proud," and "Humble" belong to the same factor, with loads of $0.83,0.92$, and 0.51 , respectively; the remaining seven emotions belong to another factor, with loads ranging from 0.49 to 0.81 (where the "calm" emotional experience load is negative). The two factors together accounted for $56.29 \%$ of the variation. According to the above results, "Pride", "Proud" and "Humble" are combined into the "Emotion 1" variable, and the other 7 emotions are combined into the "Emotional 2" variable (the "quiet" emotional experience is inversely scored.) as a control variable for later analysis. Among them, emotion $1(\mathrm{M}=3.45, \mathrm{SD}=1.25)$, emotion $2(\mathrm{M}=2.28, \mathrm{SD}=1.03)$.

Helping time: After centralizing the individual's power check score and moral self-image score, the helping time is used as the outcome variable, the sense of power check score, the moral self-image score and the product of them are used as predictors. Perform regression analysis. After controlling for gender, age, and emotion 1 and emotion 2, the results are shown in Table 2. It is found that the sense of power $(\beta=-1.299, t=-2.98, p<0.01)$ can significantly predict the individual's help time, morality. The main effect of self-image is not significant $(\beta=$ $0.17, t=0.23, p=0.82$ ), while the regression coefficient of power perception $\times$ moral self-image is significant $(\beta=1.34, t=2.41, p<0.05)$. As shown in the Table 2 .

The simple slope test found that when the moral self-image is low (M-1SD), the sense of power can significantly negatively predict the helping time $(\beta=$ $-2.24, t=-3.61, p<0.01)$; when the moral self-image is high Time-sharing $(\mathrm{M}+$ $1 \mathrm{SD})$, the sense of power cannot predict the time of help $(\beta=-0.14, t=-0.24, p$ $=0.81$ ); as shown in Figure 2 .

Table 2. The regression results of helping time.

\begin{tabular}{|c|c|c|}
\hline & \multicolumn{2}{|c|}{ Helping Time } \\
\hline & $\beta$ & $t$ \\
\hline Gender & 1.50 & 1.31 \\
\hline Age & 0.03 & 0.14 \\
\hline Emotion 1 & -0.08 & -0.52 \\
\hline Emotion 2 & -0.04 & -0.55 \\
\hline Sense of power $(\mathrm{P})$ & -1.29 & $-2.98^{* *}$ \\
\hline Moral self-image (M) & 0.17 & 0.23 \\
\hline $\mathrm{P} \times \mathrm{M}$ & 1.34 & $2.41^{\star}$ \\
\hline $\mathrm{R}^{2}$ & \multicolumn{2}{|c|}{0.11} \\
\hline $\mathrm{F}$ & \multicolumn{2}{|c|}{$2.31^{*}$} \\
\hline
\end{tabular}

Note: ${ }^{*} p<0.05,{ }^{* *} p<0.01,{ }^{* * *} p<0.001$. 


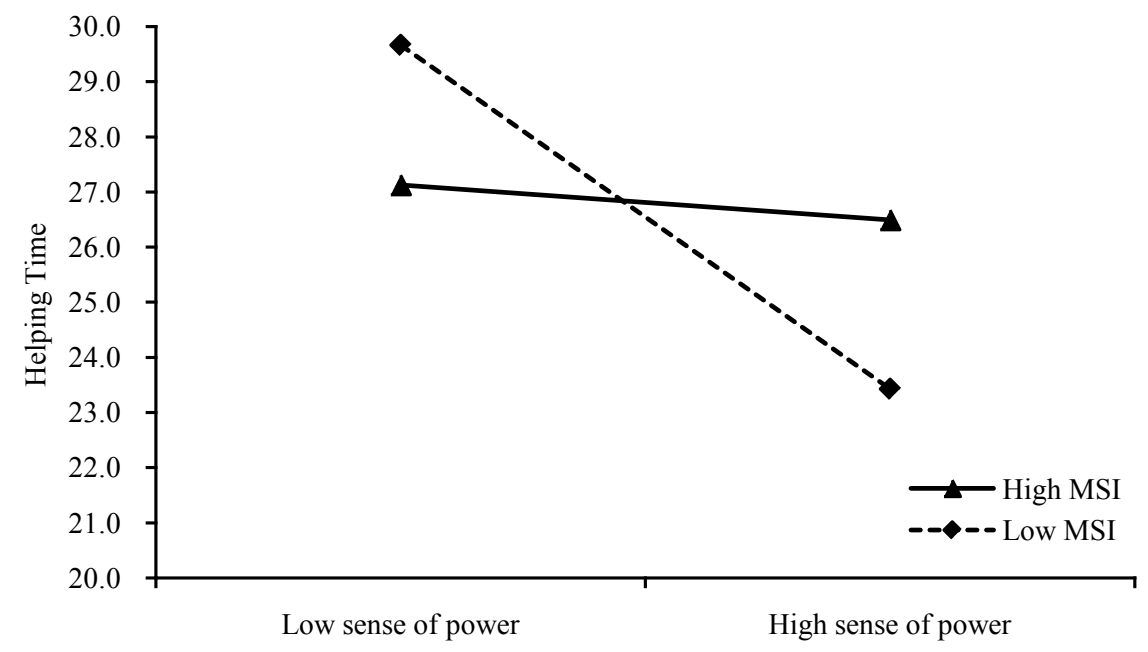

Figure 2. Simple slope test of helping time.

\subsection{Discussion}

Study $2 \mathrm{a}$ tests the individual's helping time in a simulated pro-social context, and explores the influence of sense of power and moral self-image on individual prosocial behavior. The study 2a found that the sense of power can significantly predict the individual's helping time. As the sense of power increases, the individual's help time gradually decreases. Consistent with the findings in Study 1, $\mathrm{H} 1$ is supported. Moral self-image can adjust the influence of power sense on helping people's time. Specifically, when the individual's moral self-image is low, the sense of power can significantly predict the individual's help time, and the individual helping time decreases with the increase of sense of power; when the individual's moral self-image is high, the sense of power cannot predict the individual's helping time. Consistent with the findings of Study 1, H2 is not supported. To further explore the impact of the sense of power and moral self-image on prosocial behavior, Study $2 \mathrm{~b}$ will manipulate moral self-image to further validate the findings.

\section{Study 2 b: The Effects of Sense of Power and MSI on Donation}

Study $2 \mathrm{~b}$ simultaneously manipulates the individual's sense of power and moral self-image, and further tests the findings by measuring the donation behavior of the participants through simulated charitable donation situation which is adapted by the dictator's game paradigm.

\subsection{Participants}

A total of 190 participants randomly recruit in Jinan university (none of them are majored in psychology), and 7 of them were unable to complete the recall task, these data were not included in the statistical analysis. Finally, 183 valid participants were obtained. There were 93 males and 90 females, and the average age was $22.7(\mathrm{SD}=2.31)$ years old. Participants volunteered to participate in the 
experiment and gave a certain amount of money as a thank-you after the end of the experiment.

\subsection{Methods}

The experiment used 2 (the sense of power: high, low) $\times 2$ (moral self-image: high and low) experimental design, and measured the prosocial behavior of the subject as a dependent variable through the simulated donation situation, while the subjects were the emotions are controlled.

1) The sense of power is initiated: the same as study $2 \mathrm{a}$.

2) Manipulation of moral self-image: Drawing on the method of Cornelisson (2013), different groups of participants read a set of adjectives about moral quality. After copying two times, at least two of these words were selected to describe a thing related to themselves. The participants in the high moral self-image group will see a total of 9 adjectives such as "Honesty, considerate, compassionate, and fair", while those in the low moral self-image group will see "dishonest, inconsiderate, no Compassion, injustice", and so on. After completing the transcript task, the participants need to select two of them to fill in the following sentence:

"I have done one thing, and I feel that I am This is

3) Manipulation check of the sense of power: same as study 2a.

4) Manipulation check of moral self-image: Two subjects (Cronbach's $\alpha=$ 0.72 ) are used to test the initiation of moral self-image, which is "How much do you describe the extent to which you are an ethical person" and "After describing it, how do you feel when you compare with your ideal moral self.", using 7 points score, 1 represents far less than ideal self, 7 represents far better than the ideal self.

5) Emotional Self-Assessment Questionnaire: Same as Study 2a.

\subsection{Procedures}

First, the participants were manipulated and checked for power, and the process was same as Study 2a. Then, the moral self-image is manipulated. The participants first read the corresponding nine adjectives about morality, and copy each adjective twice. After the transcription is completed, select at least two adjectives to describe the morality or not they have done. Ethical things, after completing the essay, complete the two questions of the manipulation test. Then let the participants complete the emotional scale. Finally, the measurement phase of the donation behavior, the main test informs the test that the experiment has ended. At this time, another experimental assistant informs the participant. Currently, the experiment is working with a charity event and asks whether the participant is willing to participate in the donation. The experimental income of the participants is divided into 10, if you want, you can choose any of them to make a donation. If you don't want to, you can choose 0 . After the experiment, explain to the participants that this is just the experimental design and return the donation amount to the participants. 


\subsection{Results}

Manipulation check of sense of power: Through independent sample t-test, the scores of the participants in the high-power-sensing group $(\mathrm{M}=5.15, \mathrm{SD}=$ $0.82)$ were significantly higher than those in the low-power-sense group $(\mathrm{M}=$ $2.92, \mathrm{SD}=0.63), t(181)=20.71, p<0.001$, manipulation success.

Manipulation check of moral self-image: The scores of the high MSI group $(\mathrm{M}=5.02, \mathrm{SD}=0.77)$ were significantly higher than those of the low MSI group $(\mathrm{M}=3.32, \mathrm{SD}=0.79), t(181)=14.65, p<0.001$, indicating that the MSI was successfully manipulated.

Donation behavior: Taking the amount of donation as the dependent variable, under the control of gender, age, and emotion, we launched a 2 (sense of power: high, low) $\times 2$ (moral self-image: high, Low) analysis of variance. It is found that the main effect of sense of power is significant, $\mathrm{F}(1,175)=4.36, p<$ $0.05, \eta_{p}^{2}=0.02$ The main effect of moral self-image is not significant, $\mathrm{F}(1,175)$ $=2.11, p=0.14$, The moral self-image is significantly moderate the effects of sense of power on donation, $\mathrm{F}(1,175)=5.20, p<0.05, \eta_{p}^{2}=0.03$.

The simple effect test found that when the moral self-image was low, the donation of the high-power-sense group $(\mathrm{M}=6.57, \mathrm{SD}=2.38)$ was significantly lower than that of the low-power-sense group $(\mathrm{M}=8.21, \mathrm{SD}=2.06), \mathrm{F}(1,83)=$ 7.61, $p<0.01, \eta_{p}^{2}=0.08$; when the moral self-image is high, there was no significant difference in the donation behavior between the high-power-sense group $(\mathrm{M}=8.02, \mathrm{SD}=2.38)$ and the low-power-sense group $(\mathrm{M}=7.76, \mathrm{SD}=$ 2.52), $\mathrm{F}(1,88)=0.03, p=0.87$, as shown in Figure 3.

\subsection{Discussion}

Study $2 \mathrm{~b}$ measured the prosocial behavior of the subjects by simulating the donation situation as a dependent variable, and explored the influence of power and moral self-image on prosocial behavior by manipulated the sense of power and moral self-image. It was found that the high-power-sense participants' donation

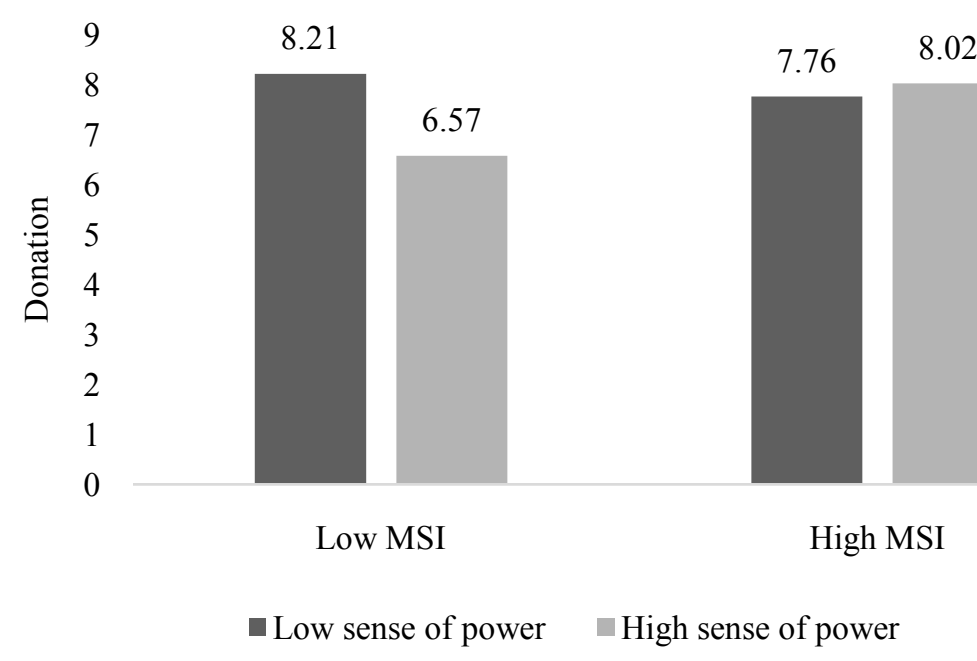

Figure 3. Simple slope test of helping time. 
behavior was significantly less than that of the low-power-sense participants, which supported $\mathrm{H} 1$, which is consistent with the conclusion of study $2 \mathrm{a}$. When the moral self-image is low, the prosocial behavior of the individual decreases with the increase of sense of power. This is because the individuals with high sense of power tend to use the promotion focus, so the individuals with high sense of power are recollecting their own immorality. Behaviors strengthen the goal of self-interest, so the level of donation behavior of individuals with high power will be relatively low; for individuals with low power, these subjects tend to use prevention focus, lower moral self-image makes it feel a sense of crisis. It needs to make some prosocial behaviors to improve the cognition of its own moral level and make the moral self-image close to the appropriate level. Therefore, the level of donation behavior of low-power-sense individuals will be relatively high.

The results of the study $2 \mathrm{a}$ and study $2 \mathrm{~b}$ can be found that when the individual's moral self-image is low, the research results are consistent with the hypothesis, but when the moral self-image is high, the hypothesis cannot be supported. We can think that regardless of the level of moral self-image, the pro-social level of low-power-sense individuals is always at a relatively high level, which means that there is no balance of prosocial behavior, which may be because of the relative powerful Individuals, the lower sense of power can't fully express the individual's own traits, so when the individual's moral self-image is high, this part of the low-power-sense, high moral self-image individual considers the moral self-image is higher than the self-interest, that is to say, the individual does not want to lose the existing moral self-image, or it may be because the design of personal interest (money and time) in the experiment does not completely balance impact of moral self-image loss.

\section{Study 3: The Mechanism of Moderated Role of MSI}

Based on Study 2, Study 3 will manipulate sense of power through role-playing methods. At the same time, considering the level of individual selfishness can also reflect prosocial level indirectly. Therefore, Study 3 used the public goods dilemma to measure the participants' selfishness as the outcome variable.

\subsection{Participants}

A total of 84 participants were randomly recruited (none of them are majored in psychology), 4 of them were not included in the subsequent statistical analysis because they did not fill in the age and gender. Among the 43 male students $(53.8 \%)$ and 37 female students $(46.3 \%)$, the average age was 23.05 (SD = 1.92) years old. The participants received a small amount of reward after completing the experiment.

\subsection{Methods and Procedures}

The experiment uses a mixed design in which the sense of power is the variable 
between the subjects and the moral self-image is the internal variable of the subject. At the beginning of the experiment, the participants were told that the experiment required two participants to complete the construction task called Tanagram. Specifically, the Tanagram task was introduced to the participants, and the demographic data of the subjects were collected before the experiment.

1) Manipulation of sense of power: First fill in the false leadership questionnaire and be told that the characters in Tanagram will be assigned according to the score of the questionnaire. In fact, all the characters are randomly assigned. After the role is assigned, the master tries to be Try to issue the corresponding instructions and let the participants read the instructions carefully.

2) Construct Tanagram: The participants in the role of leader selected three of the given sample materials and let the builders build. In the process, the leader can freely order the builder, and the builder must obey the leader's command.

3) Manipulation check of sense of power: After completing the construction of Tanagram, let the subject complete the item of manipulation check.

4) Dependent variable measurement: Inform the participants that the experiment has ended. They can get the corresponding rewards. The main test will give the participants the guidance materials for prosocial behavior measurement, and let the participants decide how many points to go.

5) Perceived responsibility measurement: The Perceived Responsibility Scale compiled by Winterich and Zhang (2014), which contains a total of 4 items (Cronbach's $\alpha=0.79$ ).

\subsection{Results}

Manipulation check of sense of power: Through independent sample t-test, it was found that the scores of the high-power-sense group $(M=5.49, S D=0.36)$ were significantly higher than those of the low-power-sense group $(\mathrm{M}=4.26$, SD $=0.47), t(78)=13.29, p<0.05$, indicating that the sense of power was successfully manipulated.

We use hierarchical linear regression to analysis the effect of the sense of power and moral self-image on perceived responsibility (Ye \& Wen, 2013).

Using self-interested behavior as a dependent variable for stratified regression analysis, after controlling for gender, age, and emotions 1,2 , sense of power has a significant positive predictive effect on individual self-interest behavior ( $\beta$ $=0.47, t=2.93, p<0.01$ ), which validates $\mathrm{H} 1$; moral self-image has no predictive effect on self-interested behavior $(\beta=-0.19, t=-0.98, p=0.33)$, while the product of sense of power and MSI has a significant predictive effect on the self-interested behavior $(\beta=-0.35, t=-2.91, p<0.01)$. To further examine the moderated effects, a simple slope analysis was performed, and it was found that for individuals with low moral self-images, the sense of power can significantly predict their self-interested behavior $(\beta=0.87, t=4.07, p<0.001)$, for individuals with high moral self-image, the sense of power cannot predict their self-interested behavior ( $\beta=0.07, t=0.31, p=0.76$ ), and partially verifies $\mathrm{H} 2$, as shown in Figure 4. 


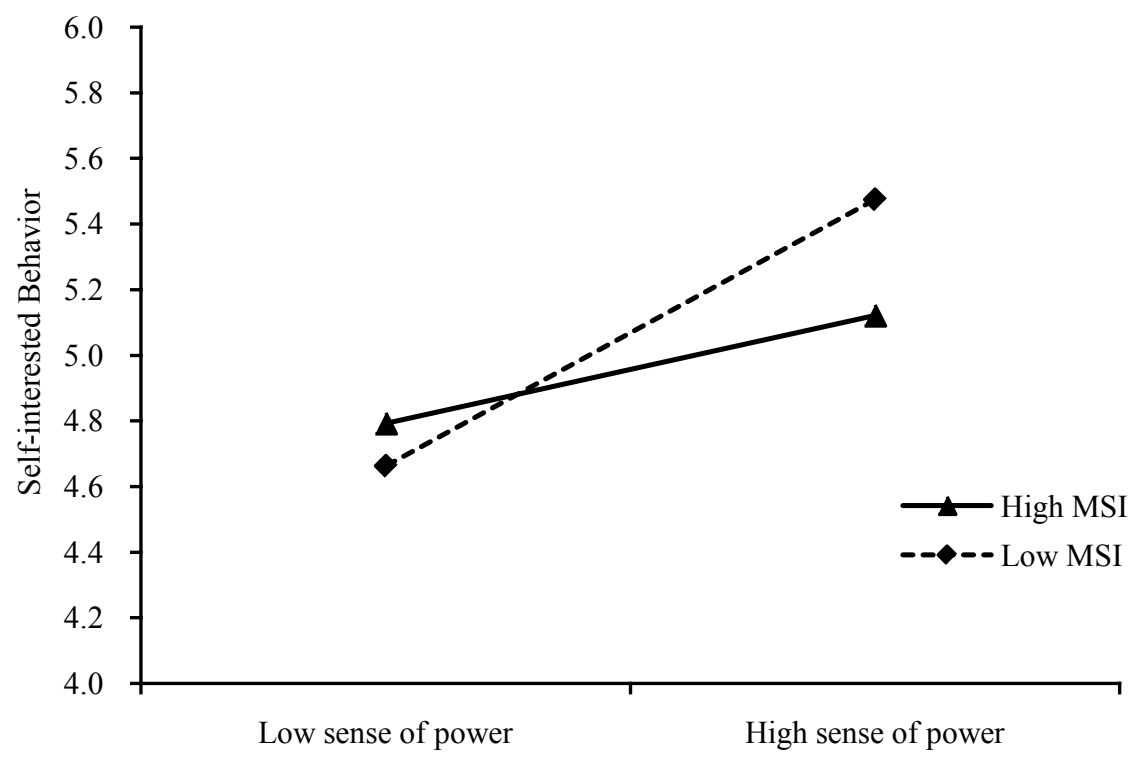

Figure 4. Simple slope test of self-interested behavior.

The study found that after adding the perceived responsibility, the product of power and moral self-image is still significant $(p<0.05)$, but its standard regression coefficient becomes smaller, which shows that sense of responsibility is in power and moral self. The image plays a part in mediating the influence on self-interested behavior. As shown in Table 3.

In order to further analyze the mediating role of perceived sense of responsibility in the sense of power and moral self-image for self-interested behavior, the process program developed by Hayes (2013) is run with an intermediary adjustment model (model 7), which has been tested by Bootstrap. The different levels of self-image were adjusted and analyzed. For those with low moral self-image, the confidence interval of Bootstrap test did not include $0(0.12,0.52)$. For those with high moral self-image, Bootstrap test, the execution interval contains 0 $(-0.19,0.08)$, that is to say, when the moral self-image is high, the sense of power has no significant predictive effect on the individual's sense of responsibility, but when the moral self-image is low, the sense of power can Significantly predict the individual's sense of responsibility, which in turn affects the level of self-interested behavior. That is to say, the sense of sense of responsibility mediates the influence of power and moral self-image on self-interested behavior. The result verifies H3. The whole regression model is as shown in Figure 5.

\subsection{Discussion}

This study explores the effects of sense of power, moral self-image on self-interested behavior and the mediating effects of perceived responsibility. The study once again supported the findings of the first two studies. First, the sense of power affects the individual's self-interested behavior. As the individual's sense of power increases, the self-interest will increase. Second, the moral self-image will adjust the sense of power. The influence of self-interested behavior is manifested in that 
Table 3. Regression result.

\begin{tabular}{|c|c|c|c|c|c|c|c|c|c|c|}
\hline & \multicolumn{4}{|c|}{ Perceived responsibility } & \multicolumn{6}{|c|}{ Self-interested behavior } \\
\hline & $B$ & $t$ & $B$ & $t$ & $B$ & $t$ & $B$ & $t$ & $B$ & $t$ \\
\hline \multicolumn{11}{|l|}{ control } \\
\hline Gender & -0.06 & -0.47 & -0.09 & -0.79 & -0.15 & -0.57 & -0.1 & -0.41 & -0.15 & -0.62 \\
\hline Age & -0.02 & -0.53 & -0.03 & -1.03 & 0.05 & 0.71 & 0.09 & 1.33 & 0.07 & 1.09 \\
\hline Emotion 1 & -0.02 & -0.46 & 0.01 & 0.22 & 0.00 & 0.04 & -0.03 & -0.32 & -0.03 & -0.27 \\
\hline Emotion 2 & 0.00 & -0.08 & -0.01 & -0.21 & 0.07 & 0.55 & 0.09 & 0.78 & 0.08 & 0.74 \\
\hline \multicolumn{11}{|l|}{$I V$} \\
\hline $\mathrm{P}$ & & & -0.17 & $-2.20^{*}$ & & & 0.47 & $2.93^{* *}$ & 0.38 & $2.37^{\star}$ \\
\hline M & & & 0.19 & $2.11^{*}$ & & & -0.19 & -0.98 & -0.09 & -0.46 \\
\hline \multicolumn{11}{|l|}{ Product } \\
\hline $\mathrm{P} \times \mathrm{M}$ & & & 0.18 & $3.13^{* *}$ & & & -0.35 & $-2.91^{\star *}$ & -0.26 & $-2.05^{\star}$ \\
\hline \multicolumn{11}{|l|}{ Mediation } \\
\hline PR & & & & & & & & & -0.52 & $-2.15^{*}$ \\
\hline $\mathrm{R}^{2}$ & \multicolumn{2}{|c|}{0.01} & \multicolumn{2}{|c|}{0.23} & \multicolumn{2}{|c|}{0.02} & \multicolumn{2}{|c|}{0.23} & \multicolumn{2}{|c|}{0.27} \\
\hline$\Delta \mathrm{R}^{2}$ & \multicolumn{2}{|c|}{0.01} & \multicolumn{2}{|c|}{0.22} & \multicolumn{2}{|c|}{0.02} & \multicolumn{2}{|c|}{0.21} & \multicolumn{2}{|c|}{0.05} \\
\hline $\mathrm{F}$ & \multicolumn{2}{|c|}{0.18} & \multicolumn{2}{|c|}{$3.09^{* *}$} & \multicolumn{2}{|c|}{0.31} & \multicolumn{2}{|c|}{$2.99^{* *}$} & \multicolumn{2}{|c|}{$3.33^{* *}$} \\
\hline
\end{tabular}

Note: ${ }^{*} p<0.05,{ }^{* *} p<0.01,{ }^{* * *} p<0.001 . P$. sense of power, M: moral self-image, PR: perceived responsibility.

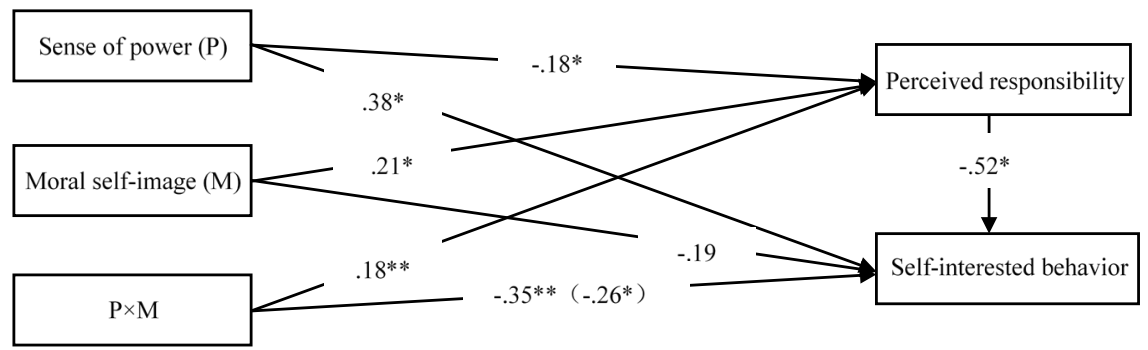

Figure 5. Regression model.

when the individual's moral self-image is low, self-interested behavior will increase with the increase of power, but when the individual's moral self-image is higher, the sense of power is self-interested. The impact of behavior is not significant. At the same time, the perception of responsibility partially mediates this effect. That is to say, when the individual's moral self-image is low, the higher the sense of power, the lower the sense of sense of responsibility, thus making his willingness to help others become lower and pay more attention to his own interests, resulting in a higher Self-interested behavior

\section{General Discussion}

The purpose of this study is to explore the influence of the sense of power on prosocial behaviors for individuals with different moral self-images, and to ex- 
plore the role of perceived responsibility in the intermediary mechanism. Among them, Study 1 measured the general sense of responsibility and the level of moral self-image by means of questionnaires, and analyzed the impact of the two on prosocial will. Study 2 manipulated the sense of power and moral self-image to further verify the influence of power and moral self-image on self-interested behavior. Study 3 uses different methods to manipulate sense of power, and further clarifies the mediated mechanism of the influence of power and moral self-image on prosocial behavior (instead of self-interested behavior in this experiment) through the plight of public goods. The above research results show that for individuals with low moral self-image, as the sense of power increases, their prosocial behavior will decrease. For individuals with high moral self-image, the sense of power cannot predict the level of prosocial behavior of individuals. At the same time, the influence of the sense of power and moral self-image on the prosocial tendencies is partly mediated by the sense of responsibility.

There will inevitably be inequalities in power in society. Differentiated power divisions mean that a small number of people will have more power, not only because this part has higher capabilities, resources and experience, but can be more effective. The decision-making helps the organization and the group to operate more efficiently, and the clear division of social power can also enable individuals at different levels to clearly understand their own rights and responsibilities and make the internal operation smoother. However, the result of this social structure in which a small number of individuals possess most of the resources will inevitably result in the fact that most low-power individuals need to rely on the resources of a small number of high-power individuals, while being influenced by high-power individual decisions. For these high-power individuals, they tend to use a method that promotes orientation, pays more attention to rewards and personal interests, and prefers to materialize others and make more self-interested behavior (Galinsky et al., 2003; Keltner et al., 2003; Lammers, Stapel, \& Galinsky, 2010), this will have a huge harm to the interests of the organization, how to guide high-power individuals to make pro-social decisions is particularly worthy of our attention.

The moral self-image as an individual's cognition of their own moral level is not only an important part of self-cognition, but also has a huge impact on our prosocial behavior. On the one hand, moral self-image and pro-social behavior show consistency, that is, the increase in prosocial behavior increases with the rise of moral self-image; on the other hand, there is also a completely opposite balance effect, that is, prosocial behavior The moral self-image is raised and lowered. Although the moral self-image will have different effects on individuals, it is not difficult to see from previous studies that when individuals recognize the moral self-image in the "ideal" framework, there will be a consistent effect, and when the individual takes the "should" framework. When you recognize your moral self-image, you will have a balanced effect.

From the perspective of moral self-image, this study is based on the regulation of orientation theory and finds that moral self-image can regulate the influence 
of power on prosocial behavior. First, consistent with the findings of previous studies, the improvement of the sense of power does make individuals more concerned with the acquisition of their own interests, reducing their prosocial levels. On the other hand, moral self-image can regulate the influence of power on the level of individual pro-social. When an individual's moral self-image is low, individuals who tend to promote orientation have a stronger awareness of their self-interested goals, and seek more personal interests, thus showing a lower level of pro-social, and in the case of low-power individuals who prevent orientation, the lower moral self-image threatens their moral self-cognition, so that individuals hope to bring their moral cognition level to an appropriate state. Therefore, individuals with low power sense will show a higher level of pro-social to maintain a more appropriate moral self-awareness. When the individual's moral self-image is high, the sense of power cannot predict the pro-social level. The pro-social level of the individual with high or low power is not significant. This may be because everyone wants to be an ethical individual. And moral self-awareness is a more central part of self-cognition (Erikson, 1964), so even for individuals with low power, they can extract the part of moral identity from the high moral self-image (Mullen \& Miller, 2016), and guided by this ethical goal, showed a high level of pro-social. This also shows from the side that compared with individuals with high sense of power, the prosocial level of individuals with low power is indeed higher.

The mediating role of perceived responsibility: This study also finds that when the individual's moral self-image is low, as the sense of power increased, the individual's sense of responsibility will decrease. This is because the high-powered person strengthens his self-interest in promoting the directed adjustment mode. Sexual goals, neglecting the sense of responsibility to help others, so their sense of sense of responsibility is low, which leads to a lower level of pro-social; and when the individual's moral self-image is higher, individuals with different senses of power have higher Perceived sense of responsibility, but also showed a high level of pro-social, perceived sense of responsibility cannot mediate the impact of the sense of power on the pro-social level, on the one hand, although for the high moral self-image/high-powerful individuals, they are promoting The directional adjustment mode strengthens its own altruistic goals, thus showing a strong sense of perceived responsibility, consistent with our hypothesis; but on the other hand, for individuals with high moral self-image/low power In this way, the prevention of directed adjustment mode makes them pay more attention to avoiding losses. They regard the higher moral self-image as completed. If you make some self-interested choices at this time, you will lose this part of your moral goals. Therefore, in order to avoid such losses, individuals with high moral self-image/low power will also show High pro-social level.

\section{Summary}

\subsection{Significance}

Until now, the research of how moral self-image affects the expression of power 
is still blank. On the one hand, our research fills in the gaps in related research, and on the other hand, it enhances the understanding of theory of power. And we hope to reveal the complexity of the effects of power through a new perspective, and try to find a new way to restrain the negative impact of power through this study. According to our conclusions, for those individuals with high power, we can reduce the negative effects brought by the improvement of power from the perspective of improving their moral self-image. For example, on the one hand, we can strengthen moral education for people with high power, and on the other hand, increasing high-power individuals' exposure to pro-social behavioral also can improve their MSI.

\subsection{Prospect}

The participants in the study used a sample of college students, although previous studies have shown that regardless of whether the individual has real power or not, sense of power can be initiated as a cognition in the individual's mind, but this sense of power is, after all, in reality. It is really a difference in power. Considering the potential impact of power perception on individuals, the results of this study are limited to the sample of college students. Therefore, we can improve the expandability of our research results by adding the participants who have real power in the future research. In addition, we find that perceived responsibility plays a mediated role in this mediated moderator model, but when the individual's moral self-image is high, the mediating effect is not significant, which indicates that there is another possible mediated variable. Future research can be further explored in this regard.

\section{Conflicts of Interest}

The authors declare no conflicts of interest regarding the publication of this paper.

\section{References}

Algoe, S. B., \& Haidt, J. (2009). Witnessing Excellence in Action: The "Other-Praising" Emotions of Elevation, Gratitude, and Admiration. The Journal of Positive Psychology, 4, 105-127. https://doi.org/10.1080/17439760802650519

Aquino, K., \& Reed, A. (2002). The Self-Importance of Moral Identity. Journal of Personality and Social Psychology, 83, 1423-1440. https://doi.org/10.1037/0022-3514.83.6.1423

Aquino, K., Reed, A., II, Thau, S., \& Freeman, D. (2007). A Grotesque and Dark Beauty: How Moral Identity and Mechanisms of Moral Disengagement Influence Cognitive and Emotional Reactions to War. Journal of Experimental Social Psychology, 43, 385-392. https://doi.org/10.1016/j.jesp.2006.05.013

Bargh, J. A., Raymond, P., Pryor, J. B., \& Strack, F. (1995). Attractiveness of the Underling: An Automatic Power Sex Association and Its Consequences for Sexual Harassment and Aggression. Journal of Personality and Social Psychology, 68, 768-781. https://doi.org/10.1037/0022-3514.68.5.768

Boehm, C., \& Flack, J. C. (2010). The Emergence of Simple and Complex Power Struc- 
tures through Social Niche Construction. In A. Guinote, \& T. K. Vescio (Eds.), The Social Psychology of Power (pp. 46-86). New York: Guilford Press.

Brass, D. J., \& Burkhardt, M. E. (1993). Potential Power and Power Use: An Investigation of Structure and Behavior. Academy of Management Journal, 36, 441-470. https://doi.org/10.2307/256588

Darley, J. M., \& Latane, B. (1968). Bystander Intervention in Emergencies: Diffusion of Responsibility. Journal of Personality and Social Psychology, 8, 377-383. https://doi.org/10.1037/h0025589

Doorn, J. V., Zeelenberg, M., \& Breugelmans, S. M. (2014). Anger and Prosocial Behavior. Emotion Review, 6, 261-268. https://doi.org/10.1177/1754073914523794

Erikson, E. H. (1964). Insight and Responsibility: Lectures on the Ethical Implications of Psychoanalytic Insight. Ethics, 76, 860.

Fiske, S. T. (1993). Controlling Other People: The Impact of Power on Stereotyping. American Psychologist, 48, 621-628. https://doi.org/10.1037/0003-066X.48.6.621

Galinsky, A. D., Gruenfeld, D. H., \& Magee, J. C. (2003). From Power to Action. Journal of Personality and Social Psychology, 85, 453-466. https://doi.org/10.1037/0022-3514.85.3.453

Galinsky, A. D., Rus, D. C., Lammers, J., Cremer, D. D., Dick, R. V., \& Murnighan, J. K. (2010). Power: A Central Force Governing Psychological, Social, and Organizational Life. In D. De Cremer, R. van Dick, \& J. K. Murnighan (Eds.), Organization and Management Series. Social Psychology and Organizations (pp. 17-38). New York: Routledge/Taylor \& Francis Group.

Gruenfeld, D. H., Inesi, M. E., Magee, J. C., \& Galinsky, A. D. (2008). Power and the Objectification of Social Targets. Journal of Personality and Social Psychology, 95, 111-127. https://doi.org/10.1037/0022-3514.95.1.111

Jordan, J., Mullen, E., \& Murnighan, J. K. (2011). Striving for the Moral Self: The Effects of Recalling Past Moral Actions on Future Moral Behavior. Personality \& Social Psychology Bulletin, 37, 701-713. https://doi.org/10.1177/0146167211400208

Julie, V. D. V., \& Abrams, D. (2015). Testing the Prosocial Effectiveness of the Prototypical Moral Emotions: Elevation Increases Benevolent Behaviors and Outrage Increases Justice Behaviors. Journal of Experimental Social Psychology, 58, 23-33. https://doi.org/10.1016/j.jesp.2014.12.005

Keltner, D., Gruenfeld, D. H., \& Anderson, C. (2003). Power, Approach, and Inhibition. Psychological Review, 110, 265-284. https://doi.org/10.1037/0033-295X.110.2.265

Lammers, J., Stapel, D. A., \& Galinsky, A. D. (2010). Power Increases Hypocrisy: Moralizing in Reasoning, Immorality in Behavior. Psychological Science, 21, 737-744. https://doi.org/10.1177/0956797610368810

Lerner, J. S., \& Tetlock, P. E. (1999). Accounting for the Effects of Accountability. Psychological Bulletin, 125, 255-275. https://doi.org/10.1037/0033-2909.125.2.255

Magee, J. C., \& Galinsky, A. D. (2008). Social Hierarchy: The Self-Reinforcing Nature of Power and Status. Academy of Management Annals, 2, 351-398. https://doi.org/10.5465/19416520802211628

Mullen, E., \& Monin, B. (2016). Consistency versus Licensing Effects of Past Moral Behavior. Annual Review of Psychology, 67, 363-385. https://doi.org/10.1146/annurev-psych-010213-115120

Rachman, S., Thordarson, D. S., Shafran, R., \& Woody, S. R. (1995). Perceived Responsibility: Structure and Significance. Behaviour Research \& Therapy, 33, 779-784. https://doi.org/10.1016/0005-7967(95)00016-Q 
Reed, A. II, Kay, A., Finnel, S., Aquino, K., \& Levy, E. (2016). I Don't Want the Money, I Just Want Your Time: How Moral Identity Overcomes the Aversion to Giving Time to Prosocial Causes. Journal of Personality and Social Psychology, 110, 435-457. https://doi.org/10.1037/pspp0000058

Rucker, D. D., Dubois, D., \& Galinsky, A. D. (2011). Generous Paupers and Stingy Princes: Power Drives Consumer Spending on Self versus Others. Journal of Consumer Research, 37, 1015-1029. https://doi.org/10.1086/657162

Rus, D. C. (2010). Power: A Central Force Governing Psychological, Social, and Organizational Life. Social Psycology \& Organizations, 21, 737-744.

Schwartz, S. H. (1977). Normative Influences on Altruism. In L. Berkowitz (Ed.), Advances in Experimental Social Psychology (Vol. 10, pp. 221-279). New York: Academic Press. https://doi.org/10.1016/S0065-2601(08)60358-5

Schwartz, S. H., \& David, A. B. (1976). Responsibility and Helping in an Emergency: Effects of Blame, Ability and Denial of Responsibility. Sociometry, 39, 406-415. https://doi.org/10.2307/3033505

Tangney, J. P., Stuewig, J., \& Mashek, D. J. (2007). Moral Emotions and Moral Behavior. Annual Review of Psychology, 58, 345-372. https://doi.org/10.1146/annurev.psych.56.091103.070145

Winterich, K. P., \& Zhang, Y. (2014). Accepting Inequality Deters Responsibility: How Power Distance Decreases Charitable Behavior. Journal of Consumer Research, 41, 274-293. https://doi.org/10.1086/675927

Wu, B., \& Yang, Z. (2018). The Impact of Moral Identity on Consumers' Green Consumption Tendency: The Role of Perceived Responsibility for Environmental Damage. Journal of Environmental Psychology, 59, 74-84. https://doi.org/10.1016/j.jenvp.2018.08.011

Ye, B., \& Wen Z. (2013). A Discussion on Testing Methods for Mediated Moderation Models: Discrimination and Integration. Acta Psychologica Sinica, 45, 1050-1060. https://doi.org/10.3724/SP.J.1041.2013.01050

Young, L., Chakroff, A., \& Tom, J. (2012). Doing Good Leads to More Good: The Reinforcing Power of a Moral Self-Concept. Review of Philosophy and Psychology, 3, 325-334. https://doi.org/10.1007/s13164-012-0111-6

Zaal, M. P., Laar, C. V., Sthl, T., Ellemers, N., \& Derks, B. (2011). By Any Means Necessary: The Effects of Regulatory Focus and Moral Conviction on Hostile and Benevolent Forms of Collective Action. British Journal of Social Psychology, 50, 670-689. https://doi.org/10.1111/j.2044-8309.2011.02069.x

Zhu, H., Wong, N., \& Huang, M. (2019). Does Relationship Matter? How Social Distance Influences Perceptions of Responsibility on Anthropomorphized Environmental Objects and Conservation Intentions. Journal of Business Research, 95, 62-70. https://doi.org/10.1016/j.jbusres.2018.10.008

Zhu, Y., Jin, S., Wan, W., \& Li, L. (2017). The Effect of Moral Self-Image on Prosocial Behavior: The Moderating Role of Regulatory Focus. Journal of Psychological Science, No. 2, 167-174. 